\title{
Testosterone Rapidly Augments Retrograde Endocannabinoid Signaling in Proopiomelanocortin Neurons to Suppress Glutamatergic Input from Steroidogenic Factor 1 Neurons via Upregulation of Diacylglycerol Lipase-a
}

\author{
Kristie Conde ${ }^{a}$ Carolina Fabelo ${ }^{a}$ William C. Krause ${ }^{b}$ Robert Propst ${ }^{a}$ \\ Jordan Goethel ${ }^{a}$ Daniel Fischer ${ }^{a}$ Jin Hur ${ }^{a}$ Cecilia Meza ${ }^{a}$ Holly A. Ingraham ${ }^{b}$ \\ Edward J. Wagnera \\ a Department of Basic Medical Sciences, College of Osteopathic Medicine, Western University of Health Sciences, \\ Pomona, CA, and ${ }^{\mathrm{b}}$ Department of Cellular and Molecular Pharmacology, University of California, San Francisco, CA, USA
}

\section{Keywords \\ Testosterone · Proopiomelanocortin · Diacylglycerol \\ lipase- $a \cdot$ Depolarization-induced suppression \\ of excitation · 2-Arachidonoylglycerol · Estradiol}

\begin{abstract}
Testosterone exerts profound effects on reproduction and energy homeostasis. Like other orexigenic hormones, it increases endocannabinoid tone within the hypothalamic feeding circuitry. Therefore, we tested the hypothesis that testosterone upregulates the expression of diacylglycerol lipase (DAGL)a in the hypothalamic arcuate nucleus (ARC) to increase energy intake via enhanced endocannabinoidmediated retrograde inhibition of anorexigenic proopiomelanocortin (POMC) neurons. Energy intake, meal patterns, and energy expenditure were evaluated in orchidectomized, male guinea pigs treated subcutaneously with testosterone propionate $(\mathrm{TP} ; 400 \mu \mathrm{g})$ or its sesame oil vehicle $(0.1 \mathrm{~mL})$. TP rapidly increased energy intake, meal size, $\mathrm{O}_{2}$ consumption, $\mathrm{CO}_{2}$ production, and metabolic heat pro-
\end{abstract}

duction, all of which were antagonized by prior administration of the DAGL inhibitor orlistat $(3 \mu \mathrm{g})$ into the third ventricle. These orlistat-sensitive, TP-induced increases in energy intake and expenditure were temporally associated with a significant elevation in ARC DAGLa expression. Electrophysiological recordings in hypothalamic slices revealed that TP potentiated depolarization-induced suppression of excitatory glutamatergic input onto identified ARC POMC neurons, which was also abolished by orlistat $(3 \mu \mathrm{M})$, the $\mathrm{CB}_{1}$ receptor antagonist $\mathrm{AM} 251(1 \mu \mathrm{M})$, and the AMP-activated protein kinase inhibitor compound $\mathrm{C}(30 \mu \mathrm{M})$ and simulated by transient bath application of the dihydrotestosterone mimetic Cl-4AS-1 (100 nM) and testosterone-conjugated bovine serum albumin (100 nM). Thus, testosterone boosts DAGLa expression to augment retrograde, presynaptic inhibition of glutamate release onto ARC POMC neurons that, in turn, increases energy intake and expenditure. These studies advance our understanding of how androgens work within the hypothalamic feeding circuitry to affect changes in energy balance.

(c) 2016 S. Karger AG, Basel

\section{KARGER}

(C) 2016 S. Karger AG, Basel

E-Mail karger@karger.com

www.karger.com/nen
Edward J. Wagner

Department of Basic Medical Sciences, College of Osteopathic Medicine

Western University of Health Sciences, 309 E. Second Street

Pomona, CA 91766 (USA)

E-Mail ewagner@westernu.edu 


\section{Introduction}

Testosterone is the quintessential male reproductive hormone. It masculinizes the male reproductive system in utero $[1,2]$, and helps promote its maturation at puberty [3]. It also stimulates the development of sexual libido [4], and its anabolic effects are a hallmark feature of male secondary sexual characteristics [5, 6]. Given the inexorable link between reproduction and energy balance [7], it should not be surprising that testosterone has considerable effects on the latter. For example, testosterone increases appetite in both rodents [8-10] and photoperiodic animals like the Soay ram [11]. It also increases various indices of energy expenditure such as $\mathrm{O}_{2}$ consumption, $\mathrm{CO}_{2}$ production, and metabolic heat production [10], as well as the expression of uncoupling protein 1 (UCP-1) in white and brown adipose tissue [12], and it potentiates norepinephrine-induced elevations in UCP-2 expression in brown adipocytes [13]. Collectively, these effects of testosterone help explain the reduced body weight and lipolysis, increased adiposity, decreased physical activity and energy expenditure, hyperleptinemia, and dyslipidemia observed in the hypoandrogenic state $[6,9,11,12,14]$.

Testosterone's effects on energy homeostasis are due largely to its influences on the hypothalamic feeding circuitry. For example, testosterone increases orexigenic neuropeptide $\mathrm{Y}$ expression and decreases anorexigenic proopiomelanocortin (POMC) expression in the hypothalamic arcuate nucleus (ARC) $[8,11,15]$. We have previously shown that testosterone increases the inhibitory GABAergic input onto POMC neurons and potentiates retrograde, endocannabinoid-mediated presynaptic inhibition of the excitatory glutamatergic input impinging on these cells [10]. With regard to the latter, this could be attributed to enhanced endocannabinoid biosynthesis or diminished endocannabinoid breakdown.

The 2 principal endocannabinoids, 2-arachidonoylglycerol (2-AG) and $\mathrm{N}$-arachidonoylethanolamine (AEA; a.k.a. anandamide), are synthesized by the enzymes diacylglycerol lipase (DAGL) and N-acyl phosphatidylethanolamine-selective phospholipase $\mathrm{D}$, respectively [16]. In general, hypothalamic levels of 2-AG are higher than those of AEA [17-19]. Levels of both 2-AG and AEA are decreased by anorexigenic leptin [17], and increased by orexigenic ghrelin and glucocorticoids $[18,19]$. On the other hand, basal levels of both 2-AG and AEA are increased in obese $d b / d b$ mice relative to lean controls, whereas in obese $f a / f a$ rats and $o b / o b$ mice, increases in 2-AG only are observed [17]. In addition, 2-AG but not
AEA concentrations are elevated in response to fasting [20].

There are 2 DAGL isoforms, DAGL $\alpha$ and DAGL $\beta$, with the former found in comparatively greater abundance within the central nervous system [21]. DAGLa is expressed postsynaptically in dendritic spines of neurons of the hippocampus and cerebellum - and also within the hypothalamic feeding circuitry - that are in close synaptic apposition with cannabinoid $\mathrm{CB}_{1}$ receptor-bearing glutamatergic nerve terminals $[21,22]$. DAGL inhibition prevents the increase in rapid eye movement sleep and energy intake following stimulation of protease-activated receptor 1 in the lateral hypothalamic area [23]. Moreover, the ghrelin-induced reduction in glutamatergic input onto neurons in the hypothalamic paraventricular nucleus is negated following blockade of DAGL activity [19]. Both ghrelin and testosterone augment endocannabinoid tone via stimulation of AMP-activated protein kinase (AMPK) [10, 19]. Therefore, we tested the hypothesis that the hyperphagia, increased energy expenditure, and heightened retrograde inhibition of POMC neurons caused by testosterone occurs via upregulation of DAGLa in the ARC.

\section{Materials and Methods}

Animals

Adult male and female Topeka guinea pigs (316-646 g; 35-72 days of age) were either purchased from Elm Hill Breeding Labs (Chelmsford, MA, USA) or bred in-house. Nr5a1-cre mice (17-24 g; 57-99 days of age) were obtained from our collaborator, Dr. Holly Ingraham, at the University of California, San Francisco. The animals were housed under a 12:12-h light/dark cycle, with food and water available ad libitum. All procedures were approved by the Western University of Health Sciences' Institutional Animal Care and Use Committee in accordance with institutional guidelines based on NIH standards.

\section{Surgical Procedures}

All surgical procedures performed on the male guinea pigs occurred while they were anesthetized with ketamine/xylazine (33 and $6 \mathrm{mg} / \mathrm{kg}$, respectively; s.c.) and 1.5-2\% isoflurane. Stereotaxic implantation of guide cannulae into the third ventricle 2 weeks prior to experimentation had been performed as described previously [24]. Briefly, the animals were secured in a stereotaxic frame by fitting the incisors over a tooth bar and inserting blunt ear bars into the ear canals. The scalp was opened by making an incision along the midline of the skull. A single hole was drilled through the skull and the dura layer cut so that a 22-G guide cannula could be slowly lowered at an angle of $4^{\circ}$ from the vertical plane (to avoid puncturing the midsagittal sinus) to its desired location $1 \mathrm{~mm}$ above the third ventricle using the following coordinates (in $\mathrm{mm}$, measured from the bregma and the top of the cerebral cortex): $\mathrm{M} / \mathrm{L},-0.7 ; \mathrm{A} / \mathrm{P},-2.1 ; \mathrm{D} / \mathrm{V},-9.8$; and tooth bar, -5.5 . Three $3.2-\mathrm{mm}$
342

Neuroendocrinology 2017;105:341-356 DOI: $10.1159 / 000453370$
Conde/Fabelo/Krause/Propst/Goethel/ Fischer/Hur/Meza/Ingraham/Wagner 
bone anchor screws were then inserted into predrilled holes, and dental cement/acrylic was used to affix the stainless steel screws and cannula to the skull. Finally, a stylette was inserted into the guide cannula to prevent cerebrospinal fluid from entering the shaft of the cannula. The animals were then allotted 7 days of recovery prior to orchidectomy, after which an additional 7 days of recovery was allowed prior to the start of the in vivo experiments described below.

Gonadally intact Nr5a1-cre mice were anesthetized with 2\% isoflurane and placed in a stereotaxic frame. An incision was made to expose the skull, and 1 or 2 holes were drilled on either side of the midsagittal suture so that an injection needle could be slowly lowered into the dorsomedial subdivision of the ventromedial nucleus (VMN; coordinates from the bregma: AV, $-1.1 \mathrm{~mm}$; ML, $\pm 0.3 \mathrm{~mm}$; and DV,$-5.6 \mathrm{~mm}$ from the dura). A unilateral injection of a Cre recombinase-dependent viral vector containing cation channelrhodopsin-2 (AAV1.EF1a.DIO.ChR2[E123A].EYFP. WPRE.hGH; $7.2 \times 10^{12}$ genomic copies/mL; $300 \mathrm{~nL}$ total volume; University of Pennsylvania Vector Core; Addgene plasmid \#35507) or a bilateral injection of a DREADD (designer receptor exclusively activated by designer drugs)-containing viral vector (pAAVEF1a-DIO-hM3D[Gq]-mCherry; $3.8 \times 10^{12}$ genomic copies/mL; $300 \mathrm{~nL}$ total volume; University of North Carolina Vector Core; Addgene plasmid \#50460) was given over $2 \mathrm{~min}$. The injection needle remained in place for $10 \mathrm{~min}$ after infusion to allow for diffusion from the tip, after which it was slowly removed from the brain to reduce potential spread of the virus. The animals were used for experimentation 2-3 weeks later.

\section{Drugs}

Unless otherwise stated, all drugs were purchased from Tocris Bioscience (Minneapolis, MN, USA). For the behavioral experiments, testosterone propionate (TP; Sigma-Aldrich, St. Louis, MO, USA) and estradiol benzoate (Steraloids, Newport, RI, USA) were initially dissolved in punctilious ethanol to make stock concentrations of $1 \mathrm{mg} / \mathrm{mL}$. Known quantities of these stock solutions were added to the appropriate volume of sesame oil to yield final concentrations of $4 \mathrm{mg} / \mathrm{mL}$ and $100 \mu \mathrm{g} / \mathrm{mL}$, respectively, following evaporation of the ethanol. Orlistat (L-leucine, N-formyl-, [1S]-1[([2S,3S]-3-hexyl-4-oxo-2-oxetanyl)methyl]dodecyl ester) was dissolved in CES (Cremophor/ethanol/0.9\% saline; $1 / 1 / 18$; v/v/v) to a final concentration of $1.5 \mathrm{mg} / \mathrm{mL}$. Clozapine $\mathrm{N}$-oxide was dissolved in filtered $0.9 \%$ saline to a final concentration of $0.3 \mathrm{mg} / \mathrm{mL}$.

For the electrophysiology experiments, the $\mathrm{GABA}_{\mathrm{A}}$ receptor antagonist SR 95531 (6-imino-3-[4-methoxyphenyl]-1[6H]-pyridazinebutanoic acid monohydrobromide) was dissolved in ultrapure $\mathrm{H}_{2} \mathrm{O}$ to a stock concentration of $10 \mathrm{mM}$, and the stock concentration was diluted further with artificial cerebrospinal fluid (aCSF) to the working concentration of $10 \mu \mathrm{M}$. The NMDA receptor antagonist CGS 19755 (cis-4-[phosphonomethyl]-2-piperidinecarboxylic acid; $10 \mathrm{~mm}$ ) was initially dissolved in $0.1 \mathrm{~N} \mathrm{NaOH}$ and then diluted to the final volume with ultrapure $\mathrm{H}_{2} \mathrm{O}$. Aliquots of this stock solution were dissolved in aCSF to a working concentration of $10 \mu \mathrm{M}$. The AMPA receptor antagonist NBQX (2,3-dioxo6-nitro-1,2,3,4-tetrahydrobenzo[f]quinoxaline-7-sulfonamide) was dissolved in ultrapure $\mathrm{H}_{2} \mathrm{O}$ to stock concentrations of $10 \mathrm{mM}$, and the stock concentrations were diluted further with aCSF to the working concentration of $3 \mu \mathrm{M}$. The dihydrotestosterone (DHT) analog Cl-4AS-1 ([4aa,4b $\beta, 6 a a, 7 a, 9 a \beta, 9 b a, 11 a \beta]-N-[2$-chlorophenyl]-2,4a,4b,5,6,6a,7,8,9,9a,9b,10,11,11a-tetradecahydro-1,4,6a-
trimethyl-2-oxo-1H-indeno[5,4-f]quinoline-7-carboxamide) was dissolved in punctilious ethanol to a stock concentration of $1 \mathrm{mM}$, which was then diluted further with aCSF to a working concentration of $100 \mathrm{nM}$. Orlistat was dissolved in dimethyl sulfoxide to a stock concentration of $10 \mathrm{mM}$, which was then diluted further with aCSF to a working concentration of $3 \mu \mathrm{M}$. TBSA (4-androsten-17 $\beta$-ol-3-one-3 carboxymethyl oxime bovine serum albumin; Steraloids) was dissolved in DMSO to a stock concentration of $1 \mathrm{mM}$, which was then diluted further with aCSF to a working concentration of $100 \mathrm{nM}$. Compound C (6-[4-(2-[1-piperidinyl]ethoxy)phenyl]-3-[4-pyridinyl]pyrazolo[1,5-a]pyrimidine dihydrochloride) was dissolved in ultrapure $\mathrm{H}_{2} \mathrm{O}$ to stock concentrations of $30 \mathrm{mM}$, and the stock concentrations were diluted further with aCSF to the working concentration of $30 \mu \mathrm{M}$. Aliquots of the stock solutions were stored at $-20^{\circ} \mathrm{C}$ until needed for experimentation.

\section{Feeding and Metabolic Studies}

The analyses of energy balance were performed in a Comprehensive Lab Animal Monitoring System (CLAMS; Columbus Instruments, Columbus, $\mathrm{OH}$, USA) that was previously described and validated elsewhere $[10,25]$. Briefly, after a 3 -day acclimation period, energy intake, energy expenditure $\left(\mathrm{O}_{2}\right.$ consumption, $\mathrm{CO}_{2}$ production, and metabolic heat production), and meal size were monitored around the clock for 5-7 days. We calculated meal size as the amount of food eaten in a given hour divided by the number of meals in the same hour. During the 5-day monitoring phase, the animals were treated every morning at 8:00 a.m. with the DAGL inhibitor orlistat $[19,23,26]$ ( $3 \mu \mathrm{g}$; intra-third venticularly) or its CES vehicle $(2 \mu \mathrm{l}$; intra-third venticularly), and every other day with TP ( $400 \mu$ g; s.c.) or its sesame oil vehicle ( $0.1 \mathrm{~mL}$; s.c.). This treatment regimen produces physiological levels of testosterone comparable to those seen in gonadally intact males [10]. For the chemogenetic experiment, animals were injected every afternoon at 4 p.m. with clozapine $\mathrm{N}$-oxide (CNO; $0.3 \mathrm{mg} / \mathrm{kg}$; s.c.) or its $0.9 \%$ saline vehicle $(1 \mathrm{~mL} / \mathrm{kg}$; s.c.) in advance of the nocturnal peak in energy consumption occurring between 8 and 10 p.m. [25].

\section{Western Blot Analysis}

Western blotting was carried out as previously reported [10]. Briefly, at the end of the 5-day experimental period, the animals were treated once again with either TP (400 $\mu$ g; s.c.) or its sesame oil vehicle ( $0.1 \mathrm{~mL}$; s.c.), anesthetized $2 \mathrm{~h}$ later with $32 \%$ isoflurane, and rapidly decapitated. Following brain removal, 2-3 coronal slices (1 mm in thickness) spanning the rostral-caudal extent of the ARC were prepared using a guinea pig brain matrix (Ted Pella, Inc., Redding, CA, USA). The ARC was then microdissected from the slices. The ARC microdissections were homogenized in cold lysis buffer (50 mM Tris-HCl, pH 7.4, 0.5 M EDTA, 0.5 M EGTA) containing protease inhibitor cocktail (Sigma-Aldrich). Protein levels were quantified using a Bradford assay (Bio-Rad Laboratories, Hercules, CA, USA) to establish equal loading into the gel. The proteins were separated by electrophoresis on a $10 \%$ sodium dodecyl sulfate polyacrylamide gel and transferred to a nitrocellulose membrane. The membranes were blocked for $1 \mathrm{~h}$ with Odyssey blocking buffer (LI-COR Biosciences, Lincoln, NE, USA) and incubated overnight with a primary antibody directed against DAGLa (1:150; Abcam, Cambridge, MA, USA) at $4^{\circ} \mathrm{C}$. All membranes were probed with anti-GAPDH (glyceraldehyde 3-phos-
Rapid Androgenic Modulation of

Endocannabinoid-Mediated Signaling
Neuroendocrinology 2017;105:341-356 DOI: $10.1159 / 000453370$ 
phate dehydrogenase) as a loading control. They were then washed 4 times with TBST (Tris-buffered saline with Tween 20) for 10 min, followed by incubation with Odyssey infrared-conjugated secondary antibodies diluted 1:10,000 in Odyssey blocking buffer for $2 \mathrm{~h}$ at room temperature. After $4 \times 10$-min washes with TBST followed by $4 \times 10$-min washes with Tris-buffered saline, the membranes were scanned using an Odyssey infrared imager (LI-COR Biosciences). Levels of DAGLa expression were determined by calculating the ratio of DAGLa density to GAPDH density for each experimental group, and then normalizing the ratio to the values observed in the vehicle-treated animals.

\section{Electrophysiology}

Whole-cell patch recordings from ARC neurons were performed as previously described [10]. Briefly, on the day of experimentation an animal was anesthetized with $32 \%$ isoflurane and rapidly decapitated. The brain was removed from the skull and the hypothalamic area was dissected. We then mounted the resultant hypothalamic block on a cutting platform that was secured in a vibratome well filled with ice-cold, oxygenated $\left(95 \% \mathrm{O}_{2}, 5 \% \mathrm{CO}_{2}\right)$ aCSF (in mM: $\mathrm{NaCl}, 124 ; \mathrm{NaHCO}_{3}, 26$; dextrose, 10; HEPES, 10; $\mathrm{KCl}, 5 ; \mathrm{NaH}_{2} \mathrm{PO}_{4}, 2.6 ; \mathrm{MgSO}_{4}, 2$; and $\left.\mathrm{CaCl}_{2}, 1\right)$. Four to 5 coronal slices $(300 \mu \mathrm{m})$ through the rostrocaudal extent of the ARC were then cut at $1^{\circ} \mathrm{C}$. The slices were transferred to an auxiliary chamber containing room-temperature, oxygenated aCSF and kept there until electrophysiological recording.

During electrophysiological recording, the slices were maintained in a chamber perfused with warmed $\left(35^{\circ} \mathrm{C}\right)$, oxygenated aCSF in which the $\mathrm{CaCl}_{2}$ concentration was raised to $2 \mathrm{mM}$. The aCSF and all drugs (diluted with aCSF) were perfused via a peristaltic pump at a rate of $1.5 \mathrm{~mL} / \mathrm{min}$. The patch electrodes were prepared from borosilicate glass (World Precision Instruments, Sarasota, FL, USA; $1.5 \mathrm{~mm}$ OD) pulled on a P-97 Flaming/Brown puller (Sutter Instrument Co., Novato, CA, USA), and filled with the following (in $\mathrm{mM}$ ): potassium gluconate, $128 ; \mathrm{NaCl}, 10 ; \mathrm{MgCl}_{2}$, 1; EGTA, 11; HEPES, 10; ATP, 1; GTP, 0.25; and 0.5\% biocytin, adjusted to a $\mathrm{pH}$ of 7.3 with $\mathrm{KOH}$. Electrode resistances varied from 3 to $8 \mathrm{M} \Omega$.

For the guinea pig experiments, whole-cell patch recordings were performed using a MultiClamp 700A preamplifier (Axon Instruments, Foster City, CA, USA) that amplified potentials and passed current through the electrode. Membrane currents were recorded in voltage clamp with access resistances $\left(\mathrm{R}_{\mathrm{A}}\right)$ that typically range from 8 to $22 \mathrm{M} \Omega$, and underwent analog-digital conversion via a Digidata 1322A interface coupled to PCLAMP 10.5 software (Axon Instruments). For the transgenic mouse experiments, recordings were made using an Olympus BX51 W1 fixedstage scope outfitted with IR-DIC video imaging. A MultiClamp $700 \mathrm{~B}$ preamplifier (Molecular Devices, Sunnyvale, CA, USA) amplified potentials and passed current through the electrode. Membrane currents underwent analog-digital conversion with a Digidata $1550 \mathrm{~A}$ interface (Molecular Devices) coupled to pCLAMP 10.5 software. The $\mathrm{R}_{\mathrm{A}}$, as well as the resting membrane potential and the $\mathrm{R}_{\mathrm{in}}$ (input resistance), were monitored throughout the course of the recording. If the $\mathrm{R}_{\mathrm{A}}$ deviated more than $10 \%$ of its original value, the recording was ended. Low-pass filtering of the currents was conducted at a frequency of $2 \mathrm{kHz}$. The liquid junction potential was calculated to be $-10 \mathrm{mV}$, and corrected for during data analysis using pCLAMP software. All recordings were performed from a holding potential of $-75 \mathrm{mV}$.
For the optogenetic experiments, recordings were performed in slices from Nr5a1-cre mice that had been injected with a ChR2containing viral vector into the VMN 2-3 weeks prior to experimentation. Once glutamatergic steroidogenic factor 1 (SF-1)-expressing fibers (visualized with enhanced yellow fluorescent protein) impinging on an ARC neuron were encountered, functional synaptic connectivity was ascertained by applying a photostimulus (10-ms pulses delivered every 1-2 s) from an LED blue light source $(470 \mathrm{~nm})$ controlled by a variable 2A LED driver (Thorlabs, Newton, NJ, USA) that directly delivered the light path through the Olympus 40X water immersion lens to generate a fast excitatory postsynaptic current (EPSC) recorded from a holding potential of $-75 \mathrm{mV}$. Pharmacological identification of these EPSCs was determined using a combination of the ionotropic glutamate receptor antagonists NBQX $(3 \mu \mathrm{M})$ and CGS $19755(10 \mu \mathrm{M})$.

Endocannabinoid-mediated retrograde inhibition of excitatory input was assessed via depolarization-induced suppression of excitation (DSE). To elicit DSE, cells from TP- or vehicle-treated animals were given a $60-\mathrm{mV}$ depolarization ( $3 \mathrm{~s}$ in duration) from a holding potential of $-75 \mathrm{mV}$. These pulses were delivered every $60 \mathrm{~s}$ for up to 15 consecutive trials. The pulses were delivered in the presence of SR $95531(10 \mu \mathrm{M})$ to block $\mathrm{GABA}_{\mathrm{A}}$ receptor-mediated synaptic input. Prior to executing the DSE protocol, we monitored either spontaneous or evoked EPSCs (sEPSCs/eEPSCs) for 3-4 min to establish the baseline sEPSC frequency and amplitude or the eEPSC amplitude. In order to evoke EPSCs, we placed a stimulating electrode connected to a SIU5 Stimulus Isolation Unit (Grass Telefactor, Warwick, RI, USA) into the dorsomedial portion of the hypothalamic VMN. The cells received a single stimulation of $18 \mathrm{~V}$ magnitude every 1-2 s for $500 \mu \mathrm{s}$. In some experiments, we perfused orlistat $(3 \mu \mathrm{M})$ along with SR 95531 to assess the role of DAGL in the expression of DSE occurring at ARC synapses. In other experiments, either the DHT mimetic Cl-4AS-1 $(100 \mathrm{nM})$ [27] or TBSA (100 nM) was used to determine the potential for rapid, membrane-delimited androgenic signaling. To explore the role of $\mathrm{CB}_{1}$ receptor activation in the DSE occurring at VMN/ARC POMC synapses, we performed experiments in the presence of the $\mathrm{CB}_{1}$ receptor antagonist AM251 (1 $\left.\mu \mathrm{M}\right)$. Finally, to test if rapid androgen effects are elicited via a membrane androgen receptor and AMPK activation, we applied membrane-impermeant TBSA (100 nM) alone and in conjunction with the AMPK inhibitor compound C $(30 \mu \mathrm{M})$. The data were analyzed by looking at the average post-stimulation amplitude and frequency acquired from at least 3 separate trials over 5-s bins up to $20 \mathrm{~s}$ normalized to that observed under basal conditions. After recording, slices were processed for immunohistochemistry, using various phenotypic markers of ARC POMC neurons as previously documented $[28,29]$.

\section{Statistical Analyses}

Homogeneity of variance was evaluated using the Levene test. Comparisons between 2 groups were made with the Student $t$ test or the Mann-Whitney U test. Comparisons between more than 2 groups were performed using either the one-way, repeated-measures multifactorial, or rank-transformed multifactorial analysis of variance (ANOVA) followed by the least significant difference (LSD) test, or alternatively using the Kruskal-Wallis test followed by the median-notched box-and-whisker analysis. Differences were considered statistically significant if the probability was less than 0.05 . 


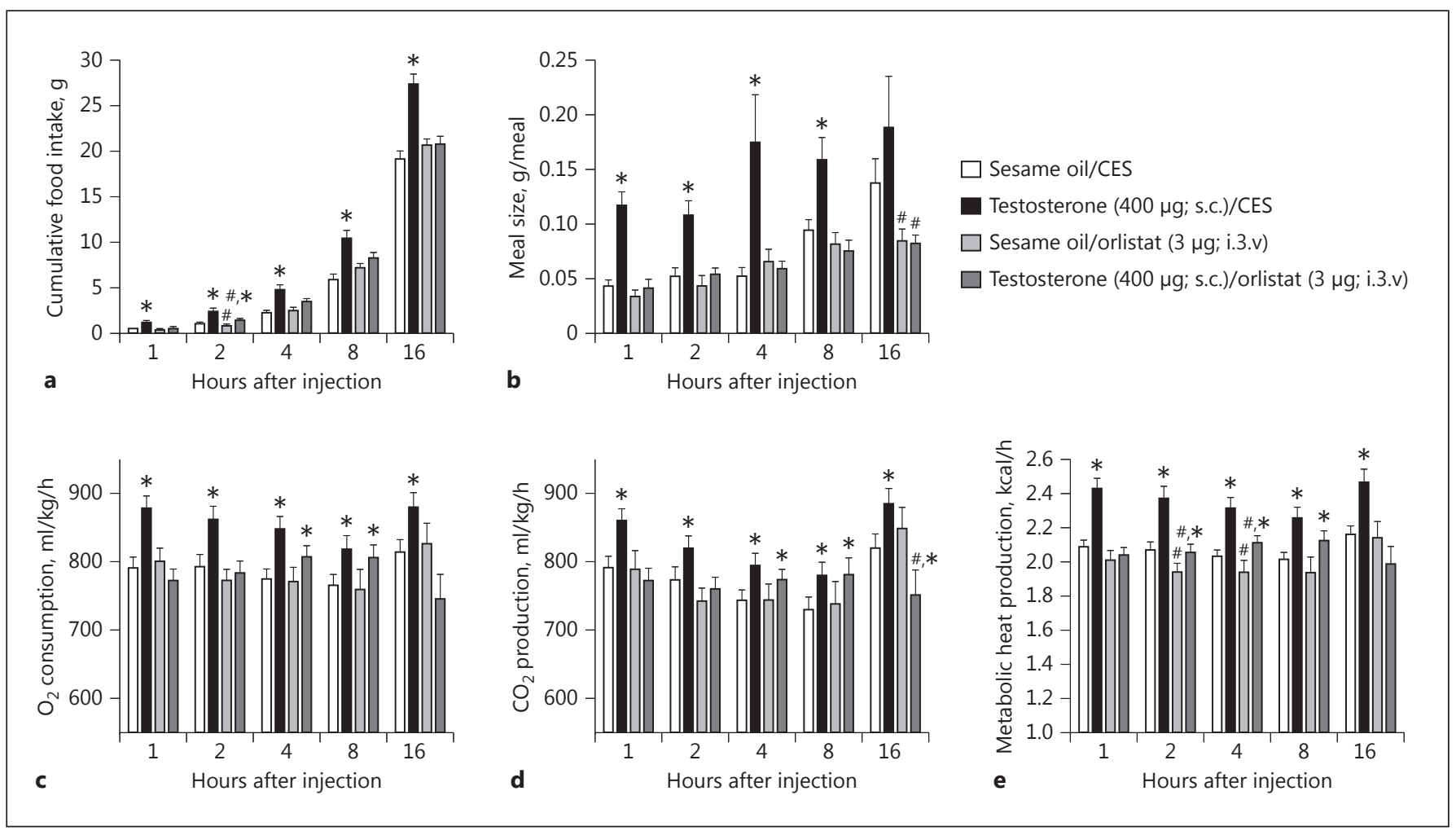

Fig. 1. The DAGL inhibitor orlistat blocks the increases in energy intake, meal size, and energy expenditure caused by TP. Bars represent means, and vertical lines 1 SEM of the food intake (a), meal size (b), $\mathrm{O}_{2}$ consumption (c), $\mathrm{CO}_{2}$ production (d), and metabolic heat production (e), which were measured $1,2,4,8$, and $16 \mathrm{~h}$ after steroid administration. Values from TP- $\left({ }^{*}\right)$ and orlistat-treated $\left(^{*}\right)$ animals that are significantly different $(p<0.05$; repeated-measures, multifactorial ANOVA/LSD; $n=4-10)$ than those obtained from vehicle-treated controls. i.3.v., intra-third venticularly.

\section{Results}

Experiment 1: The Role of DAGL in the TestosteroneInduced Changes in Energy Balance

We have demonstrated previously that testosterone augments endocannabinoid tone onto anorexigenic POMC neurons [10]. Given that DAGL is the principal enzyme involved in the biosynthesis of 2-AG that figures prominently in the endocannabinoid regulation of energy homeostasis $[17,19,21]$, we examined whether the DAGL inhibitor orlistat could prevent testosterone-induced changes in energy intake, meal pattern, and energy expenditure. Orlistat pretreatment ( $3 \mu \mathrm{g}$; intra-third venticularly) markedly diminished the ability of TP (400 $\mu \mathrm{g}$; s.c.) to increase energy intake (Fig. 1a) and meal size (Fig. 1b). It also appreciably attenuated TP-induced increases in $\mathrm{O}_{2}$ consumption, $\mathrm{CO}_{2}$ production, and metabolic heat production, effects which reliably reached statistical significance 1,2 , and again $16 \mathrm{~h}$ after administra- tion (Fig. 1c-e). To verify that testosterone is upregulating DAGLa expression in the ARC, we performed Western blotting on ARC tissue microdissected from hypothalamic slices. As shown in Figure 2, TP given $2 \mathrm{~h}$ prior to sacrifice significantly elevated ARC DAGLa expression relative to that observed in orchidectomized, vehicle-treated controls. By contrast, estradiol benzoate (10 $\mu$ g; s.c.) given to ovariectomized female guinea pigs appreciably reduced ARC DAGLa expression.

\section{Experiment 2: The Effect of the DAGL Inhibitor}

Orlistat on the Testosterone-Induced Enhancement of

Retrograde, Endocannabinoid-Mediated Inhibition of POMC Neurons

We recorded from a total of 87 guinea pig ARC POMC neurons, an example of which is represented in Figure 3. These cells exhibited a resting membrane potential of $-50.9 \pm 1.8 \mathrm{mV}$ and an $\mathrm{R}_{\mathrm{in}}$ of $818.0 \pm 97.0 \mathrm{M} \Omega$. We previously showed that testosterone heightens retrograde, en- 
Fig. 2. TP increases - whereas estradiol benzoate (EB) decreases - DAGLa expression in the ARC. a Representative Western blots illustrating the levels of DAGLa and the loading control GAPDH in the ARC microdissected from gonadectomized, steroid- and vehicle-treated animals. b, c Composite bar graphs illustrating the DAGLa/GAPDH ratio determined in ARC microdissections from animals treated $2 \mathrm{~h}$ prior with either TP, EB, or their sesame oil vehicle. Bars represent means, and vertical lines 1 SEM, respectively. * Values from steroid-treated animals that are significantly different $(p<0.05$; Mann-Whitney $\mathrm{U}$ test; $n=7-8$ ) from vehicle-treated controls.

Fig. 3. The double-labeling of an ARC neuron (arrows) that is immunopositive for a phenotypic marker characteristic of POMC neurons. a Biocytin visualized with streptavidin/Alexa Fluor 546. b a-Melanocytestimulating hormone immunoreactivity visualized with Alexa Fluor 488. c Composite overlay. $\times 40$.
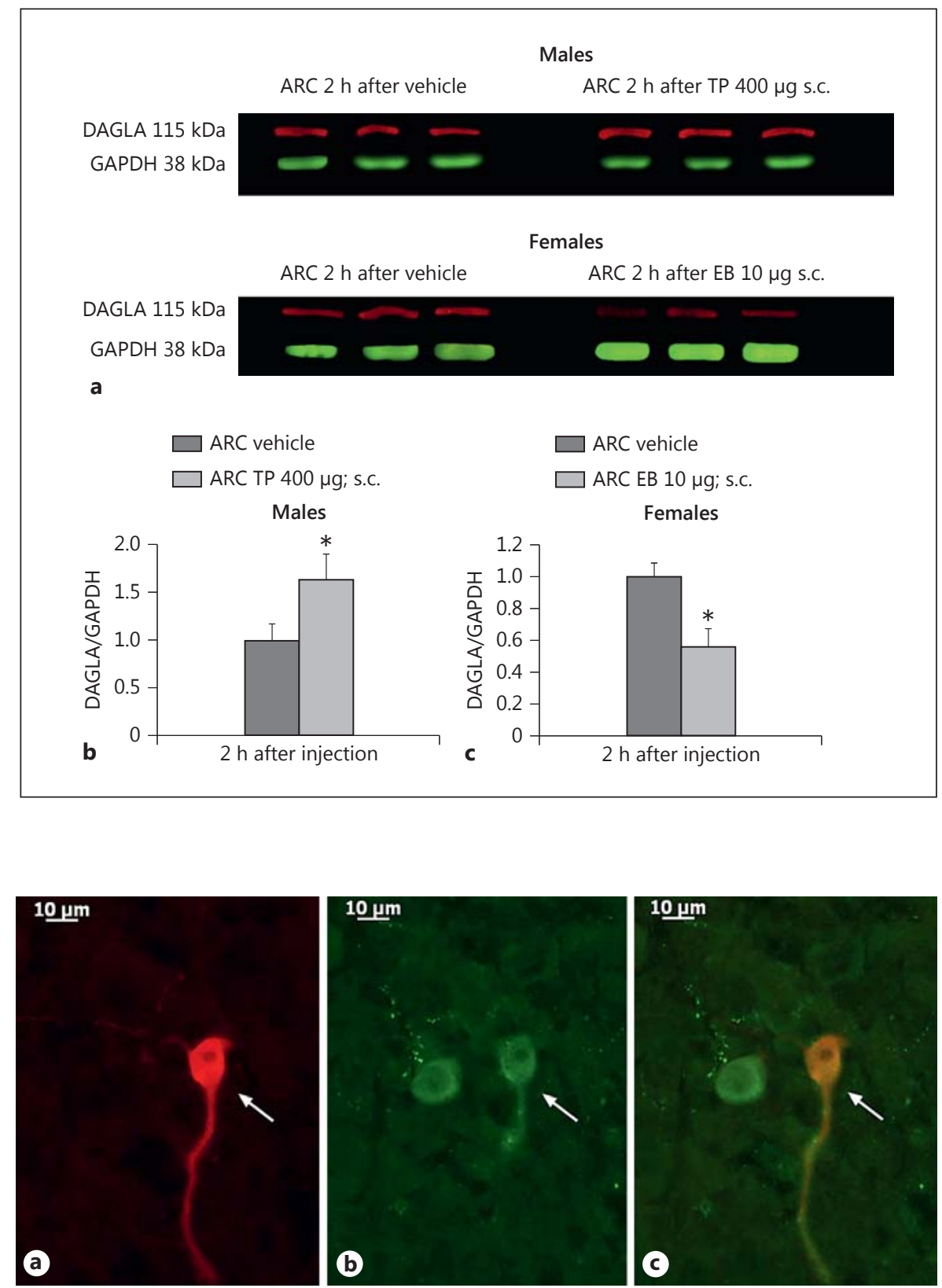

docannabinoid-mediated presynaptic inhibition of glutamatergic input onto POMC neurons [10]. Based on the findings described above, we next wanted to determine if DAGL inhibition could abrogate the testosterone-induced potentiation of DSE occurring in POMC neurons. Recordings in slices from vehicle-treated animals revealed modest reductions in sEPSC amplitude and frequency following the depolarizing stimulus $(60 \mathrm{mV}$ in magnitude, $3 \mathrm{~s}$ in duration), which were blocked in the presence of orlistat ( $3 \mu \mathrm{M}$; Fig. $4 \mathrm{a}, \mathrm{b}, \mathrm{e}, \mathrm{f})$. Recordings in slices from animals treated $24 \mathrm{~h}$ prior with $\mathrm{TP}(400 \mu \mathrm{g}$; s.c.) revealed modest yet statistically insignificant reductions in baseline sEPSC amplitude and frequency. More importantly, they uncovered DSE-induced reductions that were more prolonged and, in the case of sEPSC frequency, more pronounced (Fig. 4c-f). The more robust expression of DSE caused by systemically administered TP was also abolished by pretreatment of the slice with orlistat. 

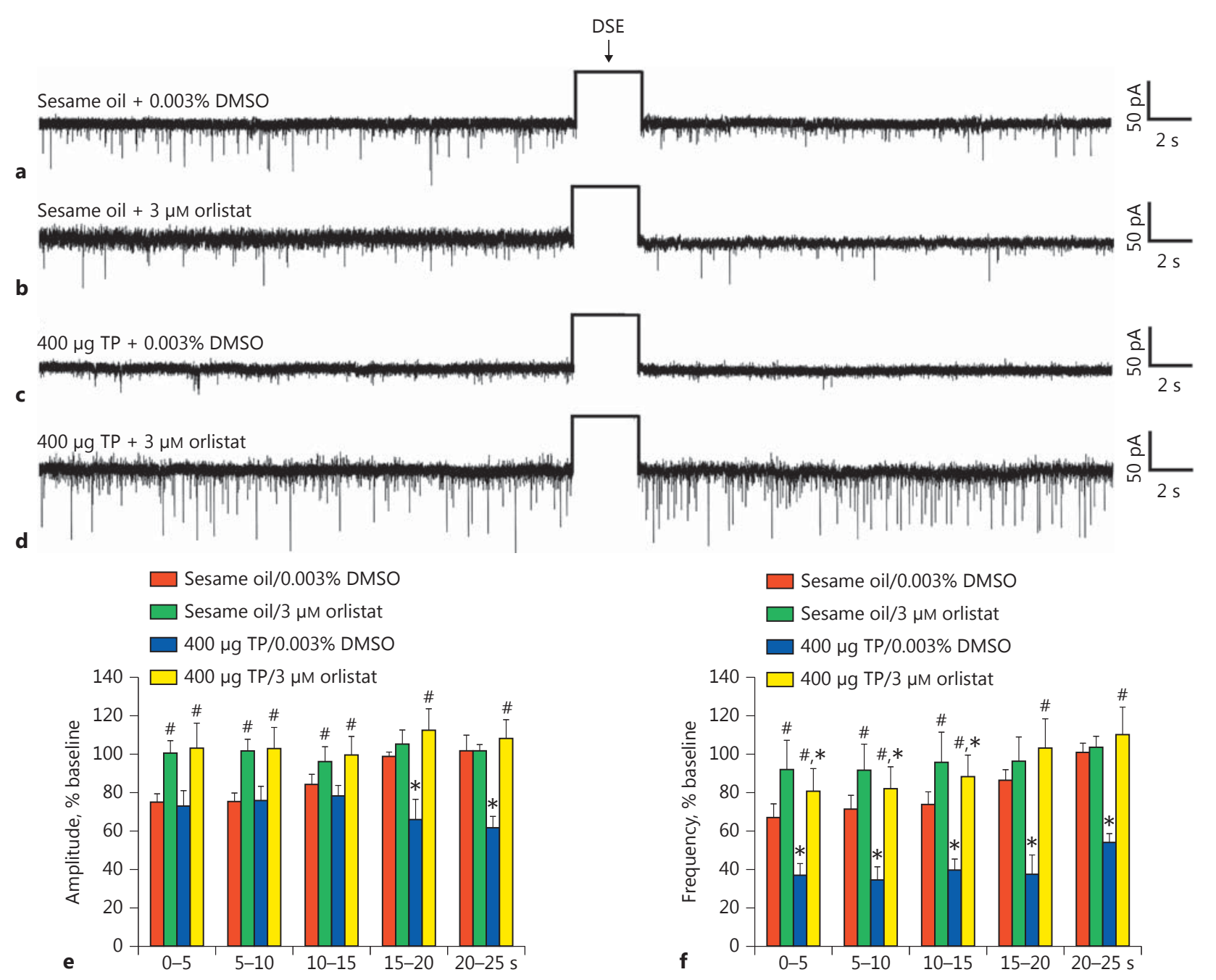

Fig. 4. The TP-induced potentiation of DSE in identified ARC POMC neurons is abolished by orlistat. The representative membrane current traces illustrate the changes in sEPSC frequency and amplitude elicited by DSE during recordings in slices from animals treated $24 \mathrm{~h}$ prior with either sesame oil vehicle $(0.1 \mathrm{~mL}$; s.c.; a, b) or TP (400 $\mu$ g; s.c.; c, d). The slices were pretreated for at least 6 min with either orlistat $(\mathbf{b}, \mathbf{d})$ or its DMSO vehicle $(\mathbf{a}, \mathbf{c})$ before electrophysiological testing. The rectangular wave under the arrow labeled "DSE" represents the truncated change in membrane current caused by the $3-\mathrm{s}, 60-\mathrm{mV}$ depolarizing voltage command. The composite bar graphs in $\mathbf{e}$ and $\mathbf{f}$ illustrate the DSE-induced chang-

Experiment 3: The Effect of a Transiently Applied DHT Mimetic on DSE-Induced Decrements in sEPSC Amplitude and Frequency in POMC Neurons

The data presented above in Figures 1 and 2 clearly indicate that testosterone produces rapid changes in ARC

Rapid Androgenic Modulation of Endocannabinoid-Mediated Signaling es in sEPSC amplitude and frequency, respectively, observed during the various treatment conditions. Bars and vertical lines represent means and 1 SEM, respectively. ${ }^{*}$ Values of post-stimulus sEPSC frequency and amplitude observed during recordings from TP-treated animals that are significantly different $(p<0.05$; ranktransformed, multifactorial ANOVA/LSD; $n=6-9$ ) than those from vehicle-treated controls. "Values of post-stimulus sEPSC frequency and amplitude observed during recordings from orlistattreated slices that were significantly different $(p<0.05$; rank-transformed, multifactorial ANOVA/LSD; $n=6-9$ ) than those from vehicle-treated slices.

DAGL $\alpha$ expression and energy balance (i.e., $<2 \mathrm{~h}$ after delivery). We therefore endeavored to ascertain whether bath application of the DHT analog Cl-4AS-1 could replicate the potentiating effect of systemically administered TP on DSE occurring in POMC neurons. As shown in 

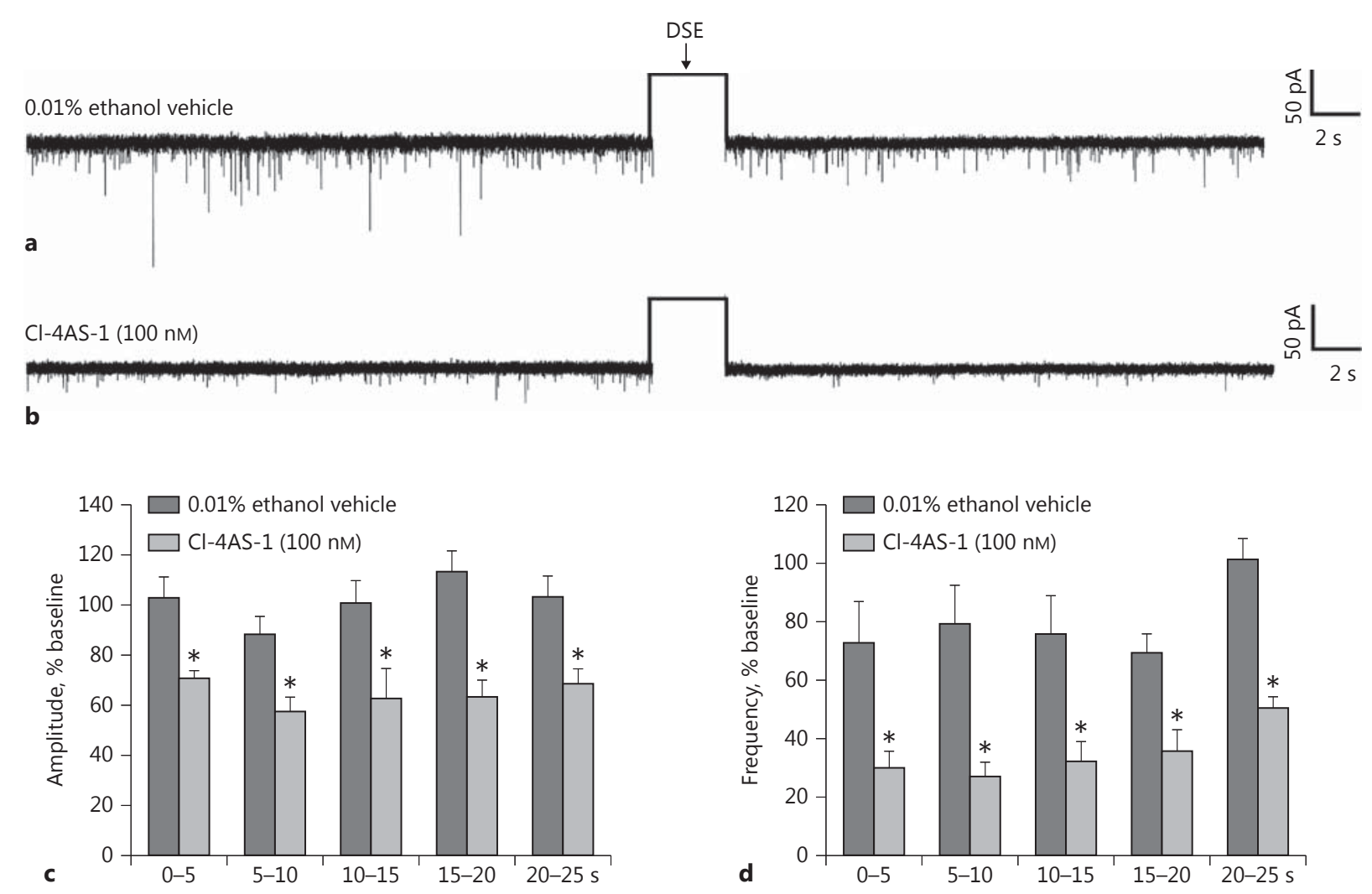

Fig. 5. Transient bath application of the DHT derivative Cl-4AS-1 mimics the TP-induced enhancement of DSE in POMC neurons. Representative membrane current traces illustrating the changes in sEPSC frequency and amplitude elicited by DSE during recordings in slices treated with ethanol vehicle (a) or Cl-4AS-1 (b). The rectangular wave under the arrow labeled "DSE" represents the truncated change in membrane current caused by the 3-s, 60-mV depolarizing voltage command. The composite bar graphs in $\mathbf{c}$ and

Figure 5, Cl-4AS-1 (100 nM) perfused over the course of the entire recording (approx. $20 \mathrm{~min}$ in duration) produced slight reductions in baseline sEPSC amplitude and frequency that were statistically insignificant. More importantly, it dramatically potentiated DSE-induced reductions in sEPSC amplitude and frequency.

Experiment 4: The Role of AMPK in the Rapid,

Membrane-Initiated Androgenic Augmentation of

Endocannabinoid/CB $B_{1}$ Receptor-Mediated Reductions

in Glutamatergic Input Emanating from SF-1

Neurons in the Dorsomedial VMN

We next wanted to determine the origin of the endocannabinoid-sensitive glutamatergic input impinging on d illustrate the DSE-induced changes in sEPSC amplitude and frequency, respectively, observed during the various treatment conditions. Bars and vertical lines represent means and 1 SEM, respectively. ${ }^{*}$ Values of post-stimulus sEPSC frequency and amplitude observed during recordings from Cl-4AS-1-treated slices that are significantly different ( $p<0.05$; Mann-Whitney U test; $n=7)$ than those from vehicle-treated slices.

POMC neurons. We chose to electrically stimulate the dorsomedial VMN due to the presence of $\mathrm{CB}_{1}$ receptorbearing glutamatergic neurons emanating from this region that are known to synaptically contact ARC POMC cells [30-32]. The distribution of stimulation sites within the VMN - as well as the recording sites within the ARC - are illustrated in Figure 6. As shown in Figure 7, stimulation of the dorsomedial VMN elicited robust eEPSCs in 48 out of 63 ARC POMC neurons, the amplitude of which was significantly greater in females than in males. Moreover, photostimulation of slices from male Nr5a1-cre mice injected with a light-activated ChR2-containing viral vector construct faithfully elicited lightevoked EPSCs in POMC neurons ipsilateral to the injec- 
Fig. 6. Coronal sections of guinea pig brain at the level of the hypothalamus that illustrate the sites of stimulation and recording within the VMN and ARC, respectively. $\mathrm{RH}$, rhomboid thalamic nucleus; RE, reuniens thalamic nucleus; PV, paraventricular hypothalamic nucleus; FX, fornix; $\mathrm{DMH}$, dorsomedial hypothalamic nucleus; $\mathrm{VMH}$, ventromedial hypothalamic nucleus; LHA, lateral hypothalamic area; MT, mammillothalamic tract; MFB, medial forebrain bundle.

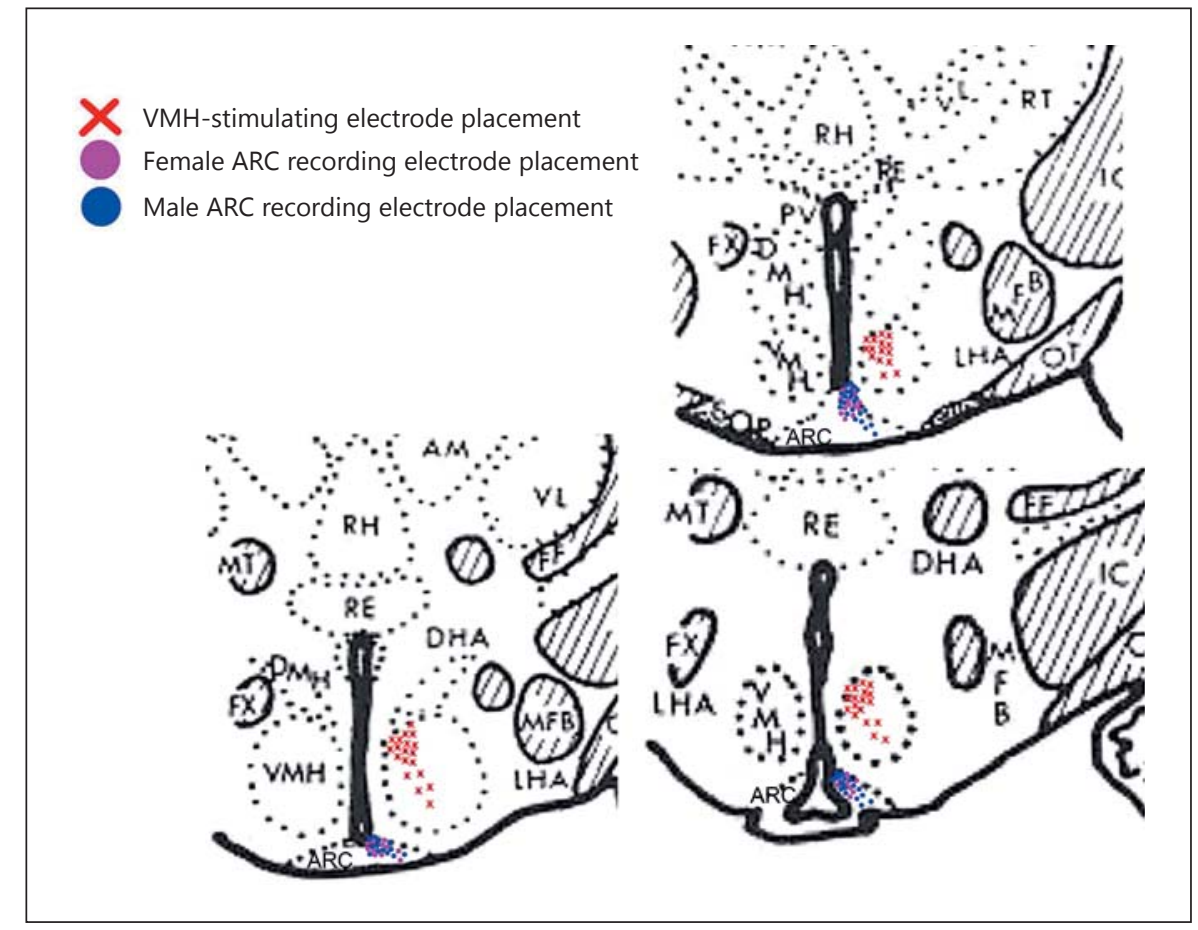

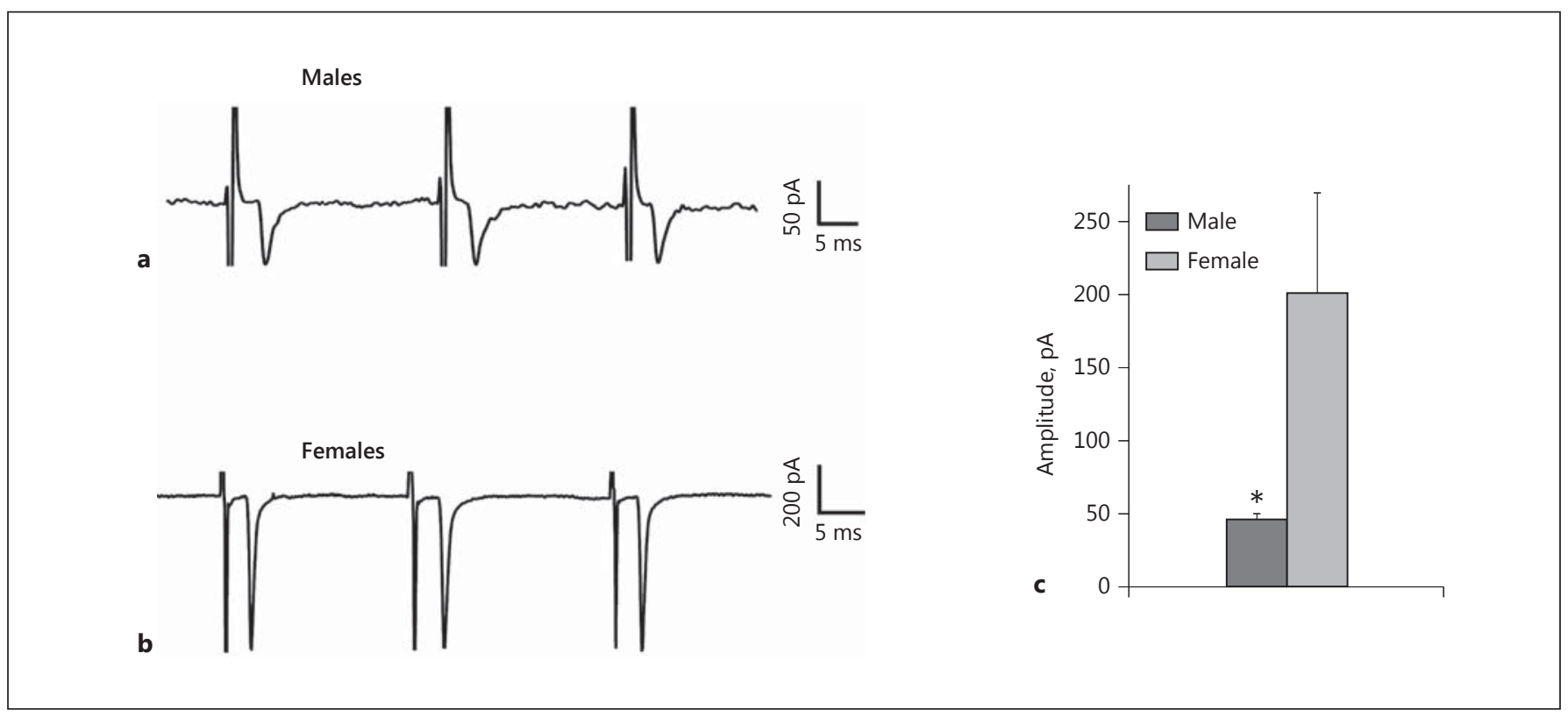

Fig. 7. The baseline amplitude of eEPSCs generated by stimulation of the dorsomedial VMN is lower in orchidectomized males than in ovariectomized females. Membrane current traces illustrating the baseline eEPSC amplitude in ARC POMC neurons are shown for both males (a) and females (b). The composite bar graph (c) further illustrates the sex differences in the amplitude of excitatory input from the dorsomedial VMN onto ARC POMC neurons under baseline conditions. Bars represent means, and vertical lines 1 SEM. ${ }^{*} p<0.05$; Mann-Whitney U test; $n=6-15$.
Rapid Androgenic Modulation of Endocannabinoid-Mediated Signaling
Neuroendocrinology 2017;105:341-356 DOI: $10.1159 / 000453370$ 


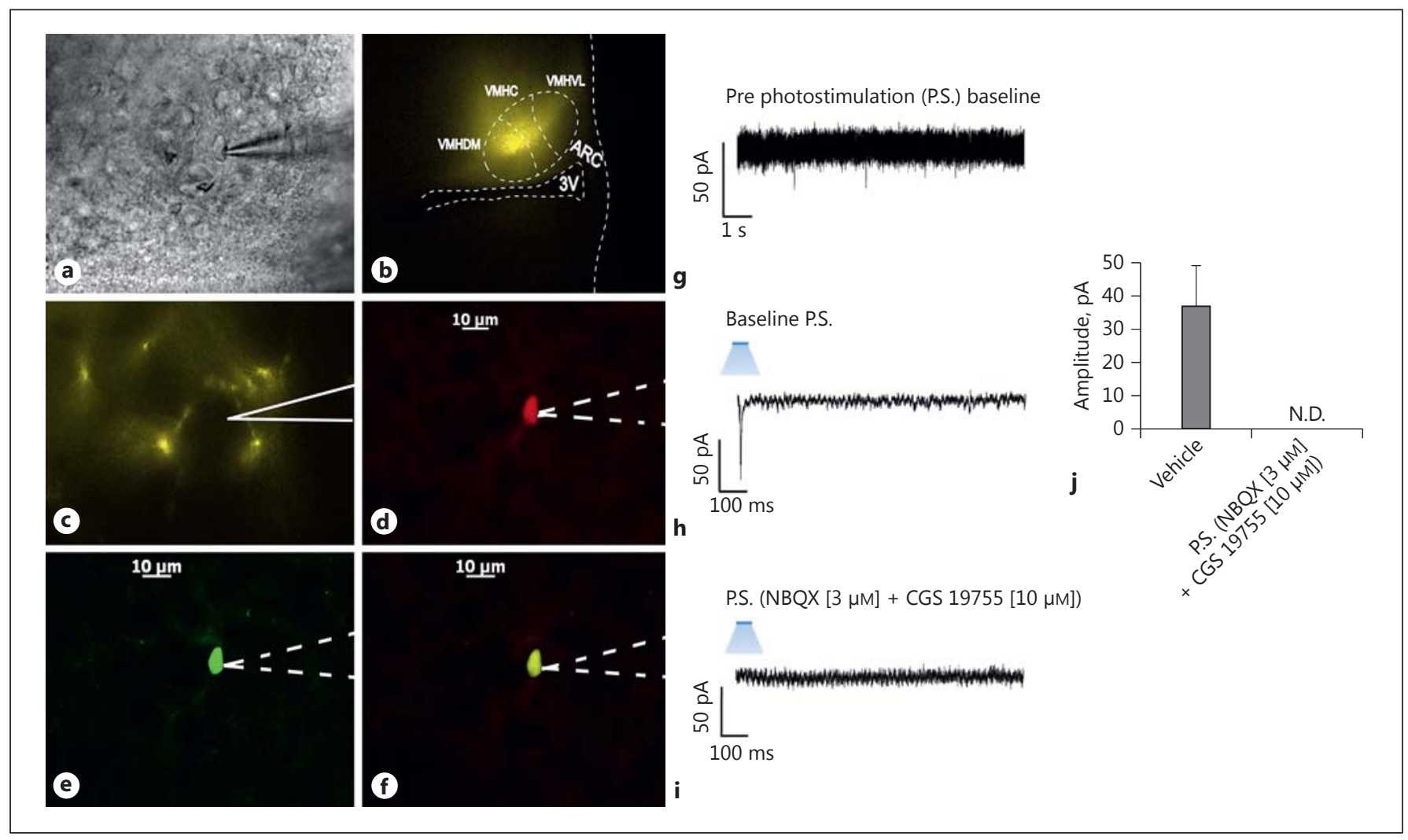

Fig. 8. Photostimulation elicits glutamatergic EPSCs at VMN SF-1/ARC POMC synapses. a An infrared, differential interference contrast image taken of a recorded ARC neuron from a male Nr5a1-cre mouse injected with a ChR2-containing virus. b ChR2 labeling in the VMN visualized at $\times 4$ with enhanced yellow fluorescent protein (eYFP). Of note is the gradient extending from the dorsomedial VMN (VMHDM) to the ventrolateral VMN (VMHVL) that is characteristic of the distribution of VMN SF-1 neurons. c Labeling of ChR2-containing fibers in the ARC visualized with eYFP. $\mathbf{d}$ Biocytin labeling of the cell in a visualized with streptavidin/Alexa Fluor 546. e An antibody directed against cocaine- and amphetamine-regulated transcript (CART), a phenotypic marker of POMC neurons, immunolabels the cell in a as visualized with Alexa Fluor 488. f A composite overlay of the biocytin/CART labeling seen in the cell in a. Unless otherwise indicated, all photomicrographs were taken at $\times 40$. The patch electrode outlined by solid lines in $\mathbf{c}$ indicates that the photomicrograph was taken during the recording, whereas those representations outlined by dashed lines in $\mathbf{d - f}$ indicate that the images were captured after processing for immunohistofluorescence. The membrane current trace in $\mathbf{g}$ shows a representative 10-s excerpt of a baseline recording of the cell in a that shows at most a few low-amplitude, spontaneous EPSCs. A 10-ms stimulus of blue light subsequently delivered to the cell in a elicited a robust EPSC (h) that was abolished by ionotropic glutamate receptor antagonists (i). The composite bar graph in $\mathbf{j}$ illustrates that the EPSC is due to the activation of ionotropic glutamate receptors. Bars represent means, and lines 1 SEM of the EPSC amplitude measured prior to - and in the presence of - the AMPA and NMDA receptor antagonists NBQX $(3 \mu \mathrm{M})$ and CGS $19755(10 \mu \mathrm{M})$, respectively $(n=10-21)$. tion site that are completely ablated in the presence of ionotropic glutamate receptor antagonists (Fig. 8). Recordings from POMC neurons contralateral to the injection site did not exhibit any such EPSCs (data not shown). The amplitude of the eEPSCs observed in POMC neurons from male guinea pig slices exhibited time-dependent DSE (Fig. 9a, 10) that was blocked by the $\mathrm{CB}_{1}$ receptor antagonist AM251 (1 $\mu \mathrm{M}$; Fig. 9b, 10). Bath application of Cl-4AS-1 prolonged the extent of the DSE (Fig. 9c, 10), which was abrogated by orlistat (Fig. 9d, 10). A similar, rapid potentiation was found with bath application of TBSA (100 nM; Fig. 11a, c), which was effectively abolished by the AMPK inhibitor compound C ( $30 \mu \mathrm{M}$; Fig. 11b, c). Importantly, we did not observe any effect of AM251, Cl-4AS-1, orlistat, TBSA, or compound C - or of DSE itself - on the $\tau_{\text {inactivation }}$ of our eEPSCs. Thus, the endocannabinoid-sensitive, glutamatergic input onto POMC neurons arises, at least in part, from SF-1 neurons in the dorsomedial VMN. These upstream VMN SF-1 neurons are clearly a critical component of the hypotha- 


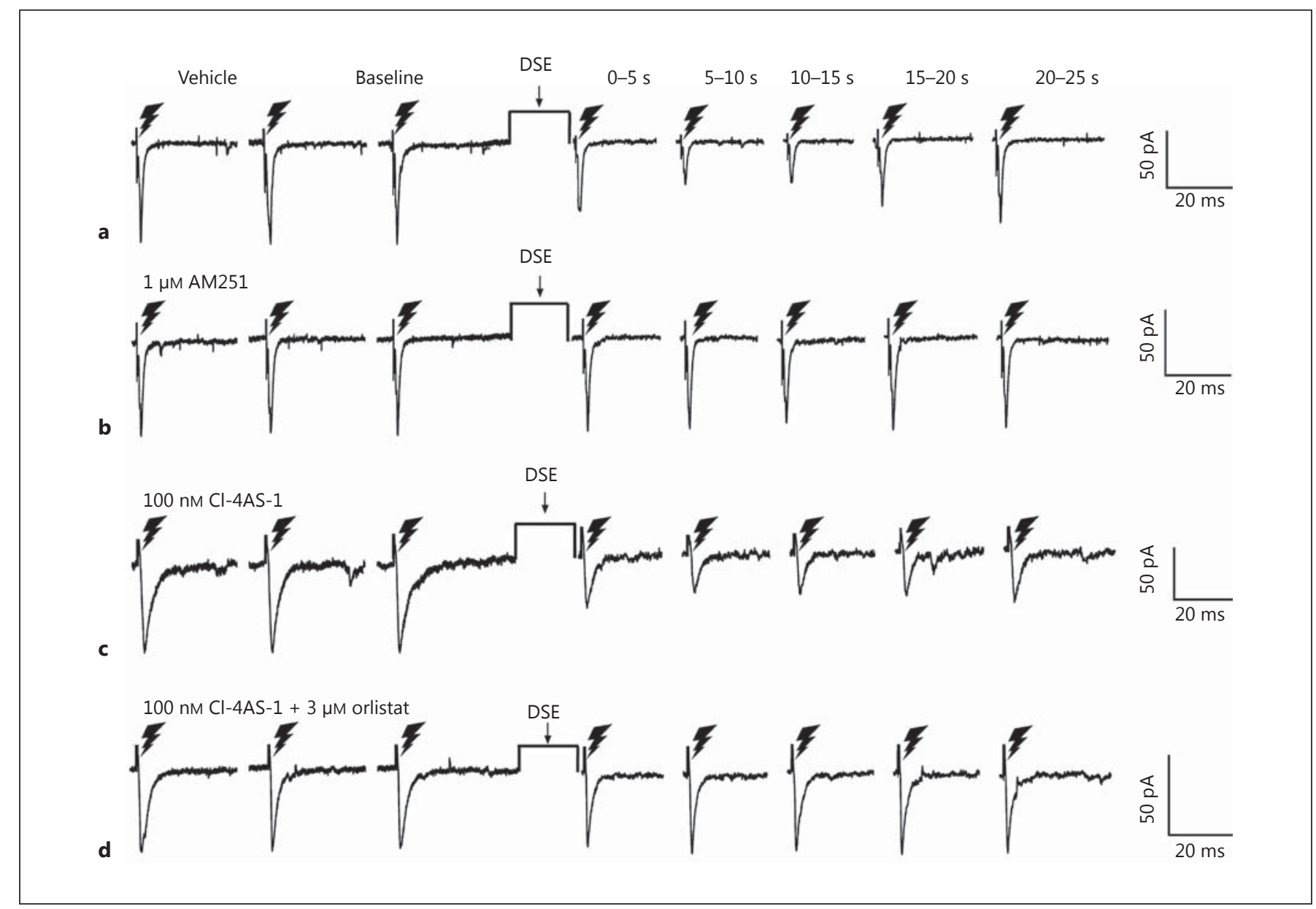

Fig. 9. DSE causes a time-dependent reduction in eEPSC amplitude through endocannabinoid signaling that is accentuated by Cl-4AS-1 and reversed with orlistat. The lightning bolts symbolize the electrical stimulation of the dorsomedial VMN delivered as described in Materials and Methods. The 3 membrane current traces on the left are representative baseline eEPSCs, while the 5 to the right of the DSE stimulus show the time-dependent DSE-

lamic energy balance circuitry, as evidenced by the fact that chemostimulation with $\mathrm{CNO}$ produced a decrease in energy intake in male Nr5a1-cre mice bilaterally injected with a modified $\mathrm{G}_{\mathrm{q}}$-coupled muscarinic M3 DREADD into the dorsomedial VMN (Fig. 12).

\section{Discussion}

The results of the present study demonstrate that testosterone rapidly enhances inhibitory endocannabinoid tone onto anorexigenic POMC neurons, which accounts, at least in part, for androgen-induced changes in energy

Rapid Androgenic Modulation of Endocannabinoid-Mediated Signaling induced changes as assessed from time bins of $0-5,5-10,10-15$, 15-20, and 20-25 s. The DSE-induced reduction in eEPSC amplitude seen in vehicle-treated slices $(\mathbf{a})$ is abolished by pretreatment with the $\mathrm{CB}_{1}$ receptor antagonist AM251 $(1 \mu \mathrm{M} ; \mathbf{b})$. Cl-4AS-1 (100 $\mathrm{nM}$ ) enhances the DSE-induced reduction in amplitude (c), which is negated by the DAGL inhibitor orlistat $(3 \mu \mathrm{M} ; \mathbf{d})$.

homeostasis. These conclusions are based on the following observations: (1) TP upregulated DAGLa expression in the ARC; (2) TP increased energy intake, meal size, and energy expenditure, all of which are blocked by the DAGL inhibitor orlistat; (3) TP augmented retrograde DSE occurring in identified POMC neurons in an orlistat-sensitive manner, which was mimicked in slices treated for mere minutes with the DHT analog Cl-4AS-1; and (4) Cl-4AS- 1 and TBSA rapidly potentiated $\mathrm{CB}_{1}$ receptormediated reductions in the amplitude of eEPSCs brought on by electrical stimulation of the dorsomedial VMN, effects that were blocked by orlistat and the AMPK inhibitor compound C. 


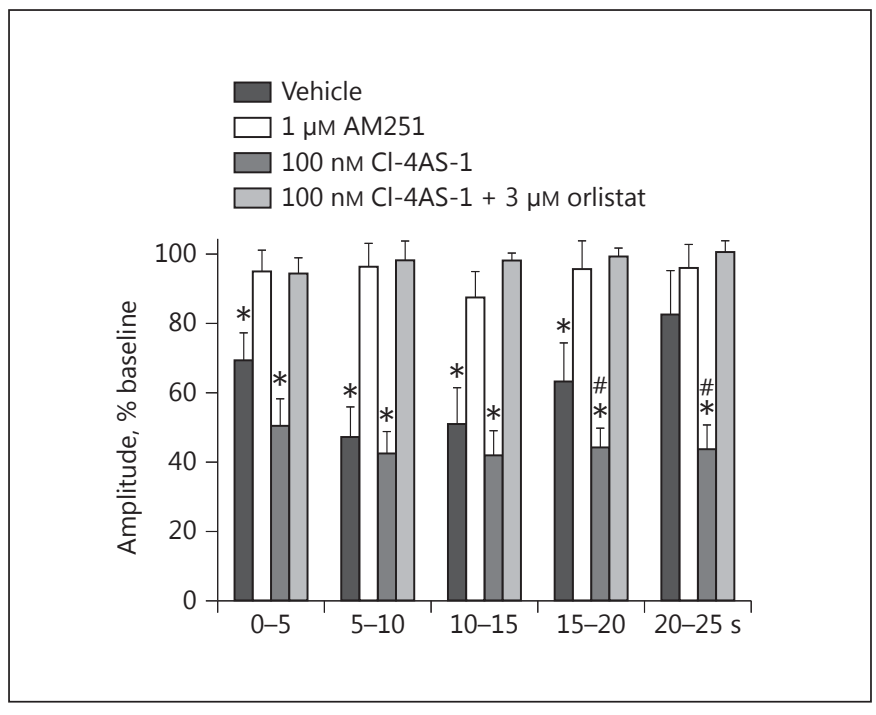

Fig. 10. Composite bar graph corresponding to Figure 9 which illustrates that the time-dependent, DSE-induced reduction in eEPSC amplitude is blocked by AM251, enhanced by Cl-4AS-1, and abrogated by orlistat. Bars and vertical lines represent means and 1 SEM, respectively. ${ }^{*}$ Values of post-stimulus eEPSC amplitudes observed during recordings from vehicle- or Cl-4AS-1-treated slices that are significantly different $(p<0.05$; Kruskal-Wallis/ median-notched box-and-whisker plot; $n=6-12$ ) than those from slices treated with either AM251 or Cl-4AS-1 plus orlistat. ${ }^{*}$ Values of post-stimulus eEPSC amplitudes observed during recordings from Cl-4AS-1-treated slices that were significantly different $(p<$ 0.05 ; Kruskal-Wallis/median-notched box-and-whisker plot; $n=$ 6-12) than those from vehicle-treated slices.

The testosterone-induced increase in energy intake observed in the present study is consistent with what we have previously described [10], as well as with the increase reported in other rodent species $[8,9]$ and photoperiodic animals [11]. Testosterone increased meal size, which is consistent with the circadian fluctuations in meal pattern seen in the guinea pig $[10,33,34]$, yet inconsistent with the increase in dark-phase meal size seen following orchidectomy in rats [35]. In addition, testosterone increased energy expenditure, which is in agreement with the fact that it increases UCP-1 expression [12], and that androgen receptor ablation and hypogonadism increase adiposity and circulating leptin, triglyceride, and fatty acid concentrations, and decrease body weight, $\mathrm{O}_{2}$ consumption, physical activity, and lipolysis $[6,9,11,12$, 14]. Lin et al. [14] reported that androgen receptor null mice also exhibit hyperglycemia and hyperinsulinemia, whereas in a study by Fan et al. [12] this was not the case. This discrepancy could be attributed to the fact that in the former study, the animals displayed reduced levels of circulating adiponectin, whereas in other studies they displayed hyperadiponectinemia $[9,12]$, which could help these animals retain their insulin sensitivity in the face of the myriad other metabolic disturbances. Collectively, it should therefore not be surprising that androgenic influences on energy intake and expenditure have been successfully leveraged in cases of hypogonadism and HIV/ AIDS-related cachexia, in which testosterone and derivatives like nandrolone increase body weight, fat-free and lean body mass, and the cross-sectional area of striated muscle $[6,36,37]$. Modest yet statistically insignificant increases in appetite and energy intake have also been reported [36].

Presently, we also found that testosterone elevated DAGLa expression in the ARC. DAGLa is chiefly responsible for the production of 2-AG in the central nervous system [21], and this endocannabinoid plays a comparatively larger role relative to AEA in regulating energy balance within the hypothalamus $[17,19]$. Conversely, estradiol reduced DAGLa expression in the ARC of ovariectomized female guinea pigs. This is important in light of the fact that the cannabinoid regulation of energy homeostasis is sexually differentiated, with males being more sensitive to the hyperphagic and hypothermic effects than females. Moreover, estradiol further dampens the cannabinoid-induced hyperphagia, hypothermia, and presynaptic inhibition of glutamatergic input onto POMC neurons via the activation of estrogen receptor- $\alpha$ and the putative, $\mathrm{G}_{\mathrm{q}}$-coupled membrane estrogen receptor, as well as the subsequent activation of phosphatidylinositol 3-kinase/ neuronal nitric oxide synthase and phospholipase $\mathrm{C} /$ protein kinase $\mathrm{C} /$ protein kinase A pathways, respectively [for a review see 38,39$]$. The hypothetical role of DAGL in the androgen-induced hyperphagia was presently affirmed by the fact that the DAGL inhibitor orlistat blocked the increase in energy intake caused by TP. This is analogous to the ghrelin-induced hyperphagia, which is altogether absent in $\mathrm{CB}_{1}$ receptor knockout mice [19].

Perhaps the most novel discovery of the present study was that orlistat also antagonized the testosterone-induced increase in energy expenditure. Cannabinoid receptor agonists are reported to inhibit cellular respiration in human sperm and cancer cells $[40,41]$. They also reduce UCP-1 and adiponectin expression in brown and white adipocytes, respectively, and increase visfatin expression in white adipocytes, to collectively inhibit thermogenesis and promote a positive energy balance [42]. In addition, we previously showed that systemic administration of the cannabinoid receptor agonist WIN 55,212-2
Conde/Fabelo/Krause/Propst/Goethel/ Fischer/Hur/Meza/Ingraham/Wagner 


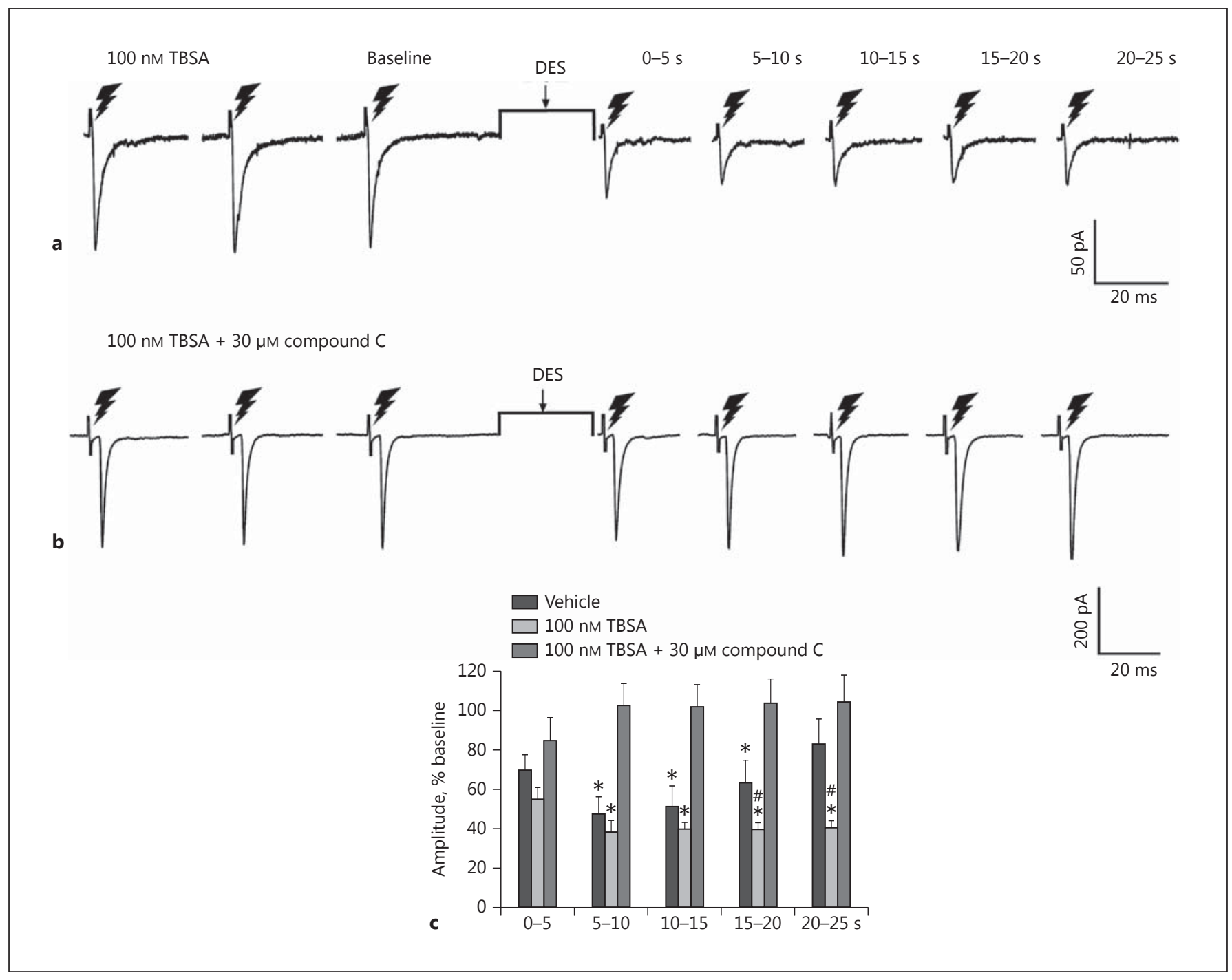

Fig. 11. TBSA mimics the enhancement of the DSE-induced reduction in eEPSC amplitude caused by Cl-4AS-1, which is abolished by the addition of the AMPK inhibitor compound C. TBSA (100 nM) intensifies the reduction in eEPSC amplitude comparably to Cl-4AS-1 (a), and this enhancement is abolished by the addition of compound C $(30 \mu \mathrm{M}$; b). The composite bar graph (c) illustrates the TBSA-induced potentiation of the retrograde, endocannabinoid-mediated decrease in glutamatergic input onto POMC neurons. Bars and vertical lines represent means and 1
SEM, respectively. * Values of post-stimulus eEPSC amplitudes observed during recordings from vehicle- or TBSA-treated slices that are significantly different $(p<0.05$; Kruskal-Wallis/mediannotched box-and-whisker plot; $n=4-10)$ than those from slices treated with TBSA in conjunction with compound C. "Values of post-stimulus eEPSC amplitudes observed during recordings from TBSA-treated slices that were significantly different $(p<0.05$; Kruskal-Wallis/median-notched box-and-whisker plot; $n=4-10$ ) than those from vehicle-treated slices. produces a slight yet statistically significant reduction in energy expenditure in ovariectomized female guinea pigs [43]. On the other hand, $\mathrm{CB}_{1}$ receptors are reportedly expressed in the mitochondrial membranes of hippocampal and hypothalamic neurons that, when activated, decrease and increase cellular respiration, respectively [44, 45]. Thus, it is conceivable that the androgenic increase in endocannabinoid tone leads to an enhanced activation of mitochondrial $\mathrm{CB}_{1}$ receptors in POMC neurons that, in turn, accounts for the testosterone-induced increase in energy expenditure.

DAGL inhibition by orlistat also blocked the increase in retrograde presynaptic inhibition of glutamatergic input onto POMC neurons caused by testosterone. This 


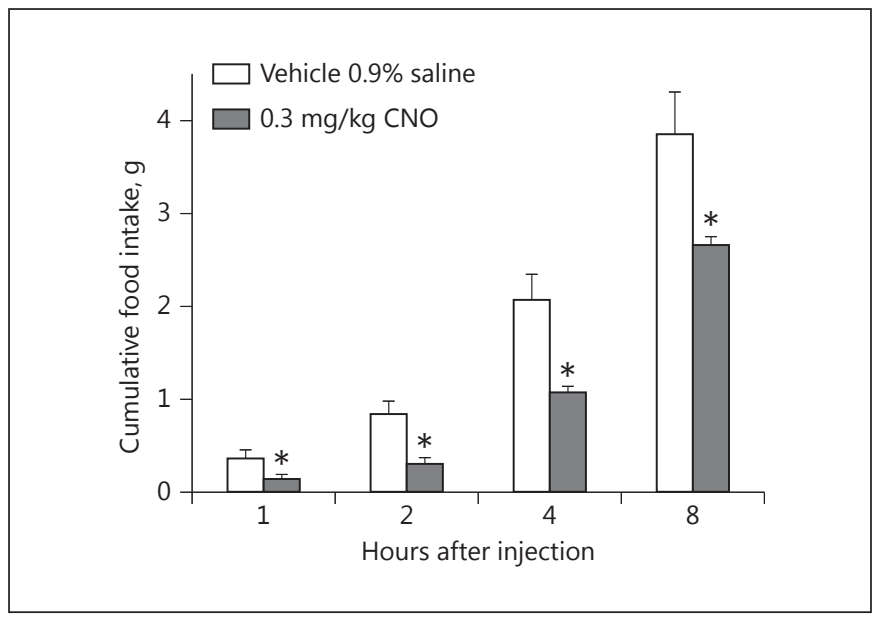

Fig. 12. Chemostimulation of VMN SF-1 neurons reduces cumulative energy take. Bars represent means, and vertical lines 1 SEM, of the food intake measured 1,2, 4, and $8 \mathrm{~h}$ after subcutaneous administration of $\mathrm{CNO}$ or its filtered $0.9 \%$ saline vehicle. ${ }^{*} p<0.05$; Student $t$ test; $n=4$.

bears a striking resemblance to the orlistat-sensitive, ghrelin-induced inhibition of glutamate release onto anorexigenic parvocellular neurons in the paraventricular nucleus [19]. Both testosterone and ghrelin activate the cellular energy sensor AMPK and increase endocannabinoid tone in the hypothalamus $[10,19,46]$. Thus, this may represent a global mechanism through which orexigenic hormones mediate their effects within the hypothalamic feeding circuitry. Another important point is that the androgenic effects on ARC DAGLa expression, energy intake and expenditure, and retrograde inhibition of POMC neurons occur on a very rapid time scale. Indeed, our data show a rapid potentiation of the DSEinduced decrease in eEPSC amplitude in slices treated with the DHT mimetic Cl-4AS-1 and the membraneimpermeant TBSA, thus revealing that androgens are binding to receptors on the plasma membrane. Additionally, inhibition of both DAGL and AMPK negates the inhibitory retrograde signaling at VMN/ARC POMC synapses. Collectively, this suggests that these actions are mediated by membrane-associated, G protein-coupled androgen receptors like those described in skeletal muscle cells [47], cardiac myocytes [48, 49], Sertoli cells [50], and colonic tumor cells [51], the activation of which leads to intracellular $\mathrm{Ca}^{2+}$ mobilization, glucose uptake, and the induction of kinase signaling pathways. The DAGL activation in postsynaptic dendrites seen with DSE is predicated upon rapid increases in intracel- lular $\mathrm{Ca}^{2+}[52,53]$. DAGLa is a multi-pass membrane protein belonging to the $\mathrm{AB}$ hydrolase superfamily whose activity is increased by rises in intracellular calcium (and presumably calcium/calmodulin-dependent protein kinase), which could stabilize the expression of the enzyme within the plasma membrane. Given the previous reports of membrane-delimited androgenic signaling demonstrating rapid increases in intracellular $\mathrm{Ca}^{2+}$, it is therefore possible that rapid, testosteroneinduced increases in intracellular $\mathrm{Ca}^{2+}$ augment DAGL activity by stabilizing its expression in the plasma membrane of POMC neurons. It stands to reason that a membrane androgen receptor would be ideally suited to subserve such a function.

In the present study, the eEPSCs were generated by electrical stimulation of the dorsomedial VMN. The baseline magnitude of these eEPSCs was sexually differentiated, with females exhibiting more robust eEPSCs than males. Given that estradiol decreases DAGL expression, it stands to reason that the comparatively larger amplitude seen in females is due to decreased endocannabinoid tone at VMN/ARC POMC synapses. The SF-1 neurons in the dorsomedial VMN are glutamatergic, express $\mathrm{CB}_{1}$ receptors [30,32], make synaptic contact with POMC neurons [31], and - as we have presently demonstrated - deliver fast EPSCs onto these cells upon photostimulation and suppress energy intake upon chemostimulation. In addition, the expression of $\mathrm{CB}_{1}$ receptors in these neurons is upregulated by SF-1 [30]. Thus, the dorsomedial VMN clearly provides a physiologically relevant source of endocannabinoid-sensitive glutamatergic input onto POMC neurons that plays a vital role in the sexually differentiated cannabinoid regulation of energy homeostasis.

In conclusion, testosterone rapidly upregulates ARC DAGLa expression through membrane-initiated signaling to potentiate the endocannabinoid-mediated retrograde inhibition of excitatory glutamatergic input impinging on anorexigenic POMC neurons in an AMPKdependent manner. These findings afford critical insight into the mechanisms through which androgens regulate energy homeostasis and efficaciously ameliorate the cachexic symptomatology associated with hypogonadism and HIV/AIDS.

\section{Acknowledgements}

This study was supported by PHS Grants DA024314 and HD058638, as well as by intramural funding from the Western University of Health Sciences.
Conde/Fabelo/Krause/Propst/Goethel/ Fischer/Hur/Meza/Ingraham/Wagner 


\section{References}

1 Davis ME, Potter EL: The response of the human fetal reproductive system to the administration of diethylstilbestrol and testosterone propionate during early pregnancy. Endocrinology 1948;42:370-378.

2 Phoenix CH, Goy RW, Gerall AA, Young WC: Organizing action of prenatally administered testosterone propionate on the tissues mediating mating behavior in the female guinea pig. Endocrinology 1959;65:369-382.

3 van Wagenen G: Maturity induced by testosterone in the young male monkey. Fed Proc 1947;6(pt 2):219.

4 Cheng P, Casida LE: Effects of testosterone propionate upon sexual libido and the production of semen and sperm in the rabbit. Endocrinology 1949;44:38-48.

5 Bardin CW: The anabolic action of testosterone. N Engl J Med 1996;335:52-53.

6 Bhasin S, Storer TW, Berman N, Yarasheski KE, Clevenger B, Phillips J, Lee WP, Bunnell TJ, Casaburi R: Testosterone replacement increases fat-free mass and muscle size in hypogonadal men. J Clin Endocrinol Metab 1997; 82:407-413.

7 Sinchak K, Wagner EJ: Estradiol signaling in the regulation of reproduction and energy balance. Front Neuroendocrinol 2012;33: 342-363.

8 Nohara K, Zhang Y, Waraich RS, Laque A, Tiano JP, Tong J, Münzberg H, Mauvais-Jarvis F: Early-life exposure to testosterone programs the hypothalamic melanocortin system. Endocrinology 2011;152:1661-1669.

9 Rana K, Fam BC, Clarke MV, Pang TPS, Zajac JD, MacLean HE: Increased adiposity in DNA binding-dependent androgen receptor knockout male mice associated with decreased voluntary activity and not insulin resistance. Am J Physiol Endocrinol Metab 2011;301:E767-E778.

10 Borgquist A, Meza C, Wagner EJ: The role of AMP-activated protein kinase in the androgenic potentiation of cannabinoid-induced changes in energy homeostasis. Am J Physiol Endocrinol Metab 2015;308:E482-E495.

11 Anukulkitch C, Rao A, Dunshea FR, Blache D, Lincoln GA, Clarke IJ: Influence of photoperiod and gonadal status on food intake, adiposity, and gene expression of hypothalamic appetite regulators in a seasonal mammal. Am J Physiol Regul Integr Comp Physiol 2007;292:R242-R252.

12 Fan W, Yanase T, Nomura M, Okabe T, Goto K, Sato T, Kawano H, Kato S, Nawata H: Androgen receptor null male mice develop lateonset obesity caused by decreased energy expenditure and lipolytic activity but show normal insulin sensitivity with high adiponectin secretion. Diabetes 2005;54:1000-1008.

13 Rodríguez AM, Monjo M, Roca P, Palou A: Opposite actions of testosterone and progesterone on UCP1 mRNA expression in cultured brown adipocytes. Cell Mol Life Sci 2002;59:1714-1723.
14 Lin H-Y, Xu Q, Yeh S, Wang R-S, Sparks JD, Chang C: Insulin and leptin resistance with hyperleptinemia in mice lacking androgen receptor. Diabetes 2005;54:1717-1725.

15 Sheppard KM, Padmanabhan V, Coolen LM, Lehman MN: Prenatal programming by testosterone of hypothalamic metabolic control neurones in the ewe. J Neuroendocrinol 2011; 23:401-411.

16 Borgquist A, Wagner EJ: On the cannabinoid regulation of energy homeostasis: past, present and future; in Murillo-Rodríguez E, Onaivi ES, Darmani NA, Wagner EJ (eds): Endocannabinoids: Molecular, Pharmacological, Behavioral and Clinical Features. Oak Park, Bentham Science, 2013, pp 60-91.

17 Di Marzo V, Goparahu SK, Wang L, Liu J, Bátkai S, Járai Z, Fezza F, Miura GI, Palmiter RD, Sugiura T, Kunos G: Leptin-regulated endocannabinoids are involved in maintaining food intake. Nature 2001;410:822-825.

18 Malcher-Lopes R, Di S, Marcheselli VS, Weng F-J, Stuart CT, Bazan NG, Tasker JG: Opposing crosstalk between leptin and glucocorticoids rapidly modulates synaptic excitation via endocannabinoid release. J Neurosci 2006; 26:6643-6650.

19 Kola B, Farkas I, Christ-Crain M, Wittmann G, Lolli F, Amin F, Harvey-White J, Liposits Z, Kunos G, Grossman AB, Fekete C, Korbonits $\mathrm{M}$ : The orexigenic effect of ghrelin is mediated through central activation of the endogenous cannabinoid system. PLoS One 2008;3:e1797

20 Kirkham TC, Williams CM, Fezza F, Di Marzo V: Endocannabinoid levels in rat limbic forebrain and hypothalamus in relation to fasting, feeding and satiation: stimulation of eating by 2-arachidonyl glycerol. Br J Pharmacol 2002;136:550-557.

21 Yoshida T, Fukaya M, Uchigashima M, Miura E, Kamiya H, Kano M, Watanabe M: Localization of diacylglycerol lipase- $\alpha$ around postsynaptic spine suggests close proximity between production site of an endocannabinoid, 2-arachidonyl-glycerol, and presynaptic cannabinoid CB1 receptor. J Neurosci 2006; 26:4740-4751.

22 Di Marzo V, Ligresti A, Cristino L: The endocannabinoid system as a link between homeostatic and hedonic pathways involved in energy balance regulation. Int J Obes (Lond) 2009;33(suppl 2):S18-S24.

23 Pérez-Morales M, López-Colomé AM, Méndez-Díaz M, Ruiz-Contreras AE, ProspéroGarcía O: Inhibition of diacylglycerol lipase (DAGL) in the lateral hypothalamus of rats prevents the increase in REMS and food ingestion induced by PAR1 stimulation. Neurosci Lett 2014;578:117-121.

24 Borgquist A, Meza C, Wagner EJ: Role of neuronal nitric oxide synthase in the estrogenic attenuation of cannabinoid-induced changes in energy homeostasis. J Neurophysiol 2015; 113:904-914.
25 Farhang B, Pietruszewski L, Lutfy K, Wagner EJ: The role of the NOP receptor in regulating food intake, meal pattern, and the excitability of proopiomelanocortin neurons. Neuropharmacology 2010;59:190-200.

26 Hashimotodani Y, Ohno-Shosaku T, Yamazaki M, Sakimura K, Kano M: Neuronal protease-activated receptor 1 drives synaptic retrograde signaling mediated by the endocannabinoid 2-arachidonoylglycerol. J Neurosci 2011;31:3104-3109.

27 Schmidt A, Harada S-I, Kimmel DB, Bai C Chen F, Rutledge SJ, Vogel RL, Scafonas A, Gentile MA, Nantermet PV, McElwee-Witmer S, Pennypacker B, Masarachia P, Sahoo SP, Kim Y, Meissner RS, Hartman GD, Duggan ME, Rodan GA, Towler DA, Ray WJ: Identification of anabolic selective androgen receptor modulators with reduced activities in reproductive tissues and sebaceous glands. J Biol Chem 2009;284:36367-36376.

28 Ho J, Cox JM, Wagner EJ: Cannabinoid-induced hyperphagia: correlation with inhibition of proopiomelanocortin neurons? Physiol Behav 2007;92:507-519.

29 Borgquist A, Rivas VM, Kachani M, Sinchak K, Wagner EJ: Gonadal steroids differentially modulate the actions of orphanin FQ/nociceptin at a physiologically relevant circuit controlling female sexual receptivity. J Neuroendocrinol 2014;26:329-340.

30 Kim KW, Jo Y-H, Zhao L, Stallings NR, Chua SC, Parker KL: Steroidogenic factor 1 regulates expression of the cannabinoid receptor 1 in the ventromedial hypothalamic nucleus. Mol Endocrinol 2008;22:1950-1961.

31 Lindberg D, Chen P, Li C: Conditional viral tracing reveals that steroidogenic factor 1-positive neurons of the dorsomedial subdivision of the ventromedial hypothalamus project to the autonomic centers of the hypothalamus and hindbrain. J Comp Neurol 2013;521:3167-3190.

32 Cardinal P, André C, Quarta C, Bellocchio L, Clark S, Elie M, Leste-Lasserre T, Maitre M, Gonzales D, Cannich A, Pagotto U, Marsicano $G$, Cota $D: C_{1}$ cannabinoid receptor in SF1-expressing neurons of the ventromedial hypothalamus determines metabolic responses to diet and leptin. Mol Metab 2014;3: 705-716.

33 Hirsch E, Collier G: The ecological determinants of reinforcement in the guinea pig. Physiol Behav 1974;12:239-249.

34 Horton BJ, West CE, Turley SD: Diurnal variation in the feeding pattern of guinea pigs. Nutr Metabol 1975;18:294-301.

35 Chai J-K, Blaha V, Meguid MM, Laviano A Yang Z-J, Varma M: Use of orchidectomy and testosterone replacement to explore meal number-to-meal size relationship in male rats. Am J Physiol Regul Integr Comp Physiol 1999;45:R1366-R1373.
Rapid Androgenic Modulation of Endocannabinoid-Mediated Signaling
Neuroendocrinology 2017;105:341-356 DOI: $10.1159 / 000453370$ 
36 Batterham MJ, Garsia R: A comparison of megestrol acetate, nandrolone decanoate and dietary counselling for HIV associated weight loss. Int J Androl 2001;24:232-240.

37 Storer TW, Woodhouse LJ, Sattler F, Singh $A B$, Schroeder ET, Beck K, Padero M, Mac P, Yarasheski KE, Geurts P, Willemsen A, Harms MK, Bhasin S: A randomized, placebo-controlled trial of nandrolone decanoate in human immunodeficiency virus-infected men with mild to moderate weight loss with recombinant human growth hormone as active reference treatment. J Clin Endocrinol Metab 2005;90:4474-4482.

38 Wagner EJ: Sex differences in cannabinoidregulated biology: a focus on energy homeostasis. Front Neuroendocrinol 2016;40:101109.

39 Conde K, Meza C, Kelly MJ, Sinchak K, Wagner EJ: Estradiol rapidly attenuates ORL-1 receptor-mediated inhibition of proopiomel-

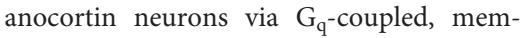
brane-initiated signaling. Neuroendocrinology 2016;103:787-805.

40 Badawy ZS, Chohan KR, Whyte DA, Penefsky HS, Brown OM, Souid A-K: Cannabinoids inhibit the respiration of human sperm. Fertil Steril 2009;91:2471-2476.

41 Whyte DA, Al-Hammadi S, Balhaj G, Brown OM, Penefsky HS, Souid A-K: Cannabinoids inhibit cellular respiration of human oral cancer cells. Pharmacology 2010;85:328-335.

42 Perwitz N, Fasshauer M, Klein J: Cannabinoid receptor signaling directly inhibits thermogenesis and alters expression of adiponectin and visfatin. Horm Metab Res 2006;38:356358.
43 Washburn N, Borgquist A, Wang K, Jeffery GS, Kelly MJ, Wagner EJ: Receptor subtypes and signal transduction mechanisms contributing to the estrogenic attenuation of cannabinoid-induced changes in energy homeostasis. Neuroendocrinology 2013;97:160-175.

44 Bénard G, Massa F, Puente N, Lourenço J, Bellocchio L, Soria-Gómez E, Matias I, Delamarre A, Metna-Laurent M, Cannich A, Hebert-Chatelain E, Mulle C, Ortega-Gutiérrez S, Martín-Fontecha M, Klugmann M, Guggenhuber S, Lutz B, Gertsch J, Chaouloff F, López-Rodríguez ML, Grandes P, Rossignol $\mathrm{R}$, Marsicano G: Mitochondrial $\mathrm{CB}_{1}$ receptors regulate neuronal energy metabolism. Nat Neurosci 2012;15:558-564.

45 Koch M, Varela L, Kim JG, Kim JD, Hernández-Nuño F, Simonds SE, Castorena CM, Vianna CR, Elmquist JK, Morozov YM, Rakic P, Bechmann I, Cowley MA, Szigeti-Buck K, Dietrich MO, Gao X-B, Diano S, Horvath TL: Hypothalamic POMC neurons promote cannabinoid-induced feeding. Nature 2015;519: $45-50$.

46 Kola B, Hubina E, Tucci SA, Kirkham TC, Garcia EA, Mitchell SE, Williams LM, Hawley SA, Hardie DG, Grossman AB, Korbonits M: Cannabinoids and ghrelin have both central and peripheral metabolic and cardiac effects via AMP-activated protein kinase. J Biol Chem 2005;280:25196-25201.

47 Estrada M, Espinosa A, Müller M, Jaimovich $\mathrm{E}$ : Testosterone stimulates intracellular calcium release and mitogen-activated protein kinases via a $G$ protein-coupled receptor in skeletal muscle cells. Endocrinology 2003; 144:3586-3597.
48 Vicencio JM, Ibarra C, Estrada M, Chiong M, Soto D, Parra V, Diaz-Araya G, Jaimovich E, Lavandero $S$ : Testosterone induces an intracellular calcium increase by a nongenomic mechanism in cultured rat cardiac myocytes. Endocrinology 2006;147:1386-1395.

49 Wilson C, Contreras-Ferrat A, Venegas N, Osorio-Fuentealba C, Pávez M, Montoya K, Durán J, Maass R, Lavandero S, Estrada M: Testosterone increases GLUT4-dependent glucose uptake in cardiomyocytes. J Cell Physiol 2013;228:2399-2407.

50 Loss ES, Jacobus AP, Wassermann GF: Rapid signaling responses in Sertoli cell membranes induced by follicle stimulating hormone and testosterone: calcium inflow and electrophysiological changes. Life Sci 2011;89:577-583.

51 Gu S, Honisch S, Kounenidakis M, Alkahtani S, Alarifi S, Alevizopoulos K, Stournaras C, Lang F: Membrane androgen receptor downregulates c-Src-activity and beta-catenin transcription and triggers GSK-3beta-phosphorylation in colon tumor cells. Cell Physiol Biochem 2014;34:1402-1412.

52 Kreitzer AC, Regehr WG: Retrograde inhibition of presynaptic calcium influx by endogenous cannabinoids at excitatory synapses onto Purkinje cells. Neuron 2001;29:717-727.

53 Rancz EA, Häusser M: Dendritic calcium spikes are tunable triggers of cannabinoid release and short-term synaptic plasticity in cerebellar Purkinje neurons. J Neurosci 2006;26: 5428-5437. 